\title{
DEVELOPMENT OF ULTRAVIOLET-SPECTROPHOTOMETRIC METHOD FOR ANALYSIS OF AMOXAPINE IN PHARMACEUTICAL DOSAGE FORM
}

\author{
SHWETA RANGARI, SHRADDHA PATIL, RUTUJA MAHAJAN, ABRAR AHMAD, NISHIKANT A RAUT* \\ Department of Pharmaceutical Sciences, Rashtrasant Tukadoji Maharaj Nagpur University, Nagpur - 440 033, Maharashtra, India. \\ Email: nishikantraut29@gmail.com
}

Received: 05 November 2017, Revised and Accepted: 08 December 2017

\begin{abstract}
Objective: Knowing the exact amount of active pharmaceutical ingredient (API) in pharmaceutical dosage form is of utmost importance to meet regulatory requirements and to ensure patient safety. Spectrophotometric analysis provides a simple, efficient, and economic approach for estimation of API in the pharmaceutical dosage form. In the present work, we have developed simple, sensitive, and highly economic ultraviolet (UV) spectrophotometric method for the estimation of amoxapine in a pharmaceutical formulation.
\end{abstract}

Methods: Amoxapine shows maximum absorbance of light at wavelength $297 \mathrm{~nm}$ in water. The linearity study revealed that it obeys Beer-Lambert's law over the range of $2-20 \mu \mathrm{g} / \mathrm{mL}$. Absorptivity value of amoxapine was found to be $206.6 \pm 1.341$.

Result: The tablet formulation was successfully analyzed by developed UV spectrophotometric method. The developed method was validated as per International Conference on Harmonization guidelines with respect to accuracy, precision, specificity robustness . The limit of detection and limit of quantitation was found to be 19.8 and $60.50 \mathrm{ng} / \mathrm{mL}$, respectively.

Conclusion: The developed method is simple, precise, accurate, and cost-effective and can be used for routine analysis of amoxapine.

Keywords: Amoxapine, Ultraviolet-spectrophotometry, Method development, Validation.

(C) 2018 The Authors. Published by Innovare Academic Sciences Pvt Ltd. This is an open access article under the CC BY license (http://creativecommons. org/licenses/by/4. 0/) DOI: http://dx.doi.org/10.22159/ajpcr.2018.v11i3.23154

\section{INTRODUCTION}

The pharmaceutical analysis is a branch of pharmaceutical sciences having immense importance in the drug development and good manufacturing practices. Knowing the exact amount of active pharmaceutical ingredient (API) in pharmaceutical dosage form is of utmost importance to meet regulatory requirements and to ensure patient safety. Spectrophotometric analysis provides a simple, efficient, and economic estimation of API in pharmaceutical dosage form $[1,2]$.

Amoxapine (Fig. 1) is a tricyclic antidepressant, acts by inhibiting reuptake of neuronal transmitter and help in controlling agitation and anxiety along with depression $[3,4]$. Chemically, amoxapine is 2-chloro11-(piperazine-1-yl) dibenzo-[b,f] [1,4] oxazepine having molecular weight $313.7 \mathrm{~g} / \mathrm{mol}$ and molecular formula $\mathrm{C}_{17} \mathrm{H}_{16} \mathrm{ClN}_{3} \mathrm{O}$ [5].

There are numerous methods available for analysis of amoxapine, such as high-performance liquid chromatography [6-9], high-performance liquid chromatography-MS/MS [10], and spectrofluorimetric method [11]. The spectrophotometric method using chromogenic reagents such as phenanthroline and naphthoquinone sulfate for color development and first-order spectrophotometric method using ethanol as a solvent are also reported [12,13]. All the methods available are either costly or time-consuming. Hence, the aim of proposed research work was to develop simple, accurate, precise, and economic ultraviolet (UV)-spectrophotometric method for estimation of amoxapine in pharmaceutical dosage form.

\section{METHODS}

\section{Instruments}

UV-1800 spectrophotometer (Shimadzu, Tokyo, Japan), with UV probe 2.52 software and $10 \mathrm{~mm}$ rectangular quartz cell was employed to develop UV-spectrophotometric method. AR2130 balance (Adventurer, New Jersey, USA) was used for all weighing procedures.
Standard, tablet formulation, chemicals, and reagents

Amoxapine (purity 99.2\%) was obtained as a gift sample from Mehta Pharmaceutical Industries, Mumbai (India). Amoxapine tablet formulation (amolife $50 \mathrm{mg}$, La Pharma, Ahmedabad, Gujarat) was purchased from regional pharmacy shop. All other chemicals and reagents (Sisco Research Laboratories Pvt., Ltd. (Mumbai, India) used were of analytical grade, procured from local vendor and used without further purification. Double-distilled water was used throughout the experiment.

\section{EXPERIMENTAL AND RESULT}

Standard stock and working solution preparation

The standard stock solution was prepared by dissolving an accurately weighed quantity of amoxapine $(10 \mathrm{mg})$ in aliquot portion of methanol and volume was made up to $10 \mathrm{ml}$ with water. The working solution was prepared by diluting the $0.1 \mathrm{ml}$ of standard stock solution with water so as to get a concentration of $10 \mu \mathrm{g} / \mathrm{ml}$.

Determination of absorbance maxima $\left(\lambda_{\max }\right)$

The amoxapine solution in water $(10 \mu \mathrm{g} / \mathrm{ml})$ was freshly prepared from stock solution and scanned in the UV range of 400-200 nm (Fig. 2) against blank. The well-defined spectrum was observed with absorbance maxima at $297 \mathrm{~nm}$.

\section{Linearity and range}

The standard stock solution was serially diluted with water to different concentrations such as $2,4,6,8,10,12,14,16,18,20,22$, $24,26,28$ and $30 \mu \mathrm{g} / \mathrm{ml}$. The absorbances of these solutions were recorded at wavelength $297 \mathrm{~nm}$. The plot of calibration curve was plotted for absorbance versus concentration (Fig. 3). The calibration curve shows the linearity over the concentration range from $2 \mu \mathrm{g} / \mathrm{mL}$ to $20 \mu \mathrm{g} / \mathrm{mL}$. 
Determination of absorptivity value

Absorptivity value was determined by weighing five different weights and preparing five dilutions for precise result. For this, the standard stock solution of amoxapine for each weight was diluted in five different volumetric flasks with water to obtain $10 \mu \mathrm{g} / \mathrm{ml}$ of concentrations. The absorbance of each solution was recorded at $297 \mathrm{~nm}$ using $10 \mathrm{~mm}$ quartz cell. The absorptivity values for five different weights were calculated using formula mentioned below. The results obtained from the absorbance of each solution were used for calculation of absorptivity value, and results are depicted in Table 1.

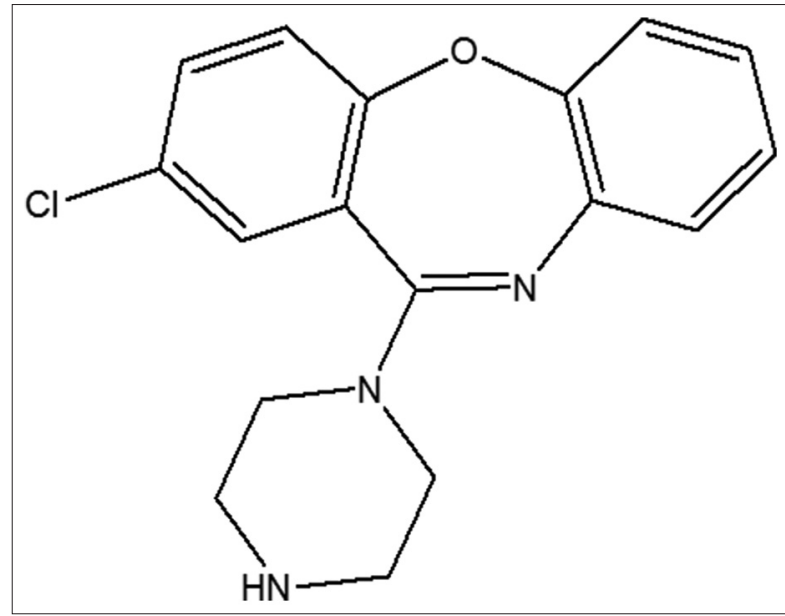

Fig. 1: Chemical structure of amoxapine

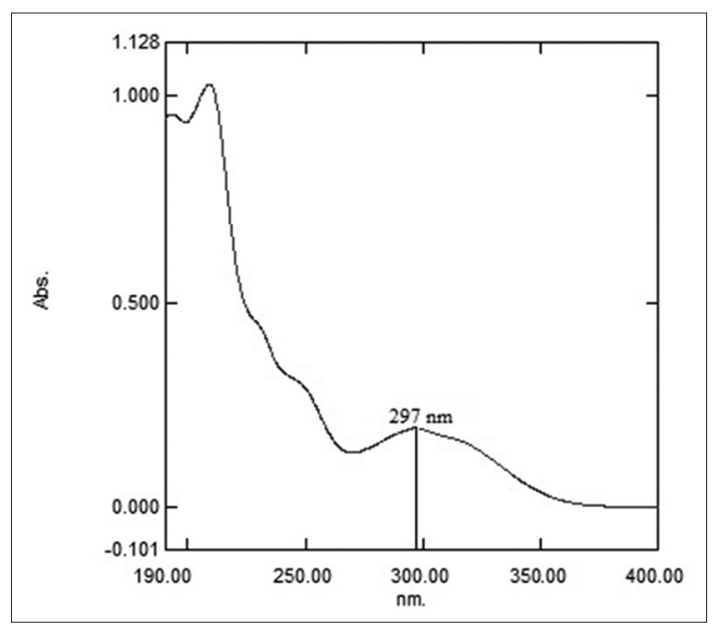

Fig. 2: Ultraviolet spectrum of amoxapine

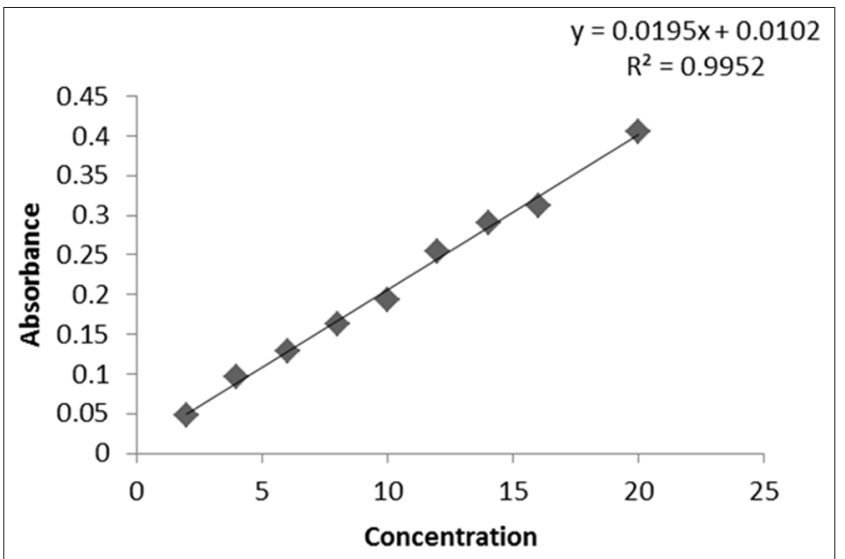

Fig. 3: Study of beer lambert's law

$$
\text { Absorptivity value }=\frac{\text { Absorbance }}{\text { Concentration of analyte }(\mathrm{g} / 100 \mathrm{ml})}
$$

Application of proposed method for analysis of tablet formulation For analyzing the tablet formulation of amoxapine, 20 tablets were weighed to the determine average weight and powdered. Accurately weighed quantities of tablet powder equivalent to $10 \mathrm{mg}$ amoxapine were transferred in $10 \mathrm{ml}$ of volumetric flask. The content of flaks was dissolved in aliquot part of methanol by vigorous shaking, and the volume was made with water. The final concentration of $10 \mu \mathrm{g} / \mathrm{ml}$ was obtained by diluting the aliquot portion of these stock solutions with water. The absorbance of these solutions was measured at $297 \mathrm{~nm}$ wavelength, and the amount of drug was estimated. The data of estimation are depicted in Table 2.

\section{Validation}

International conference on harmonization (ICH) Q2 (R1) guidelines were referred to validate the proposed method with respect to accuracy, precision, linearity, range, specificity and ruggedness [14].

\section{Accuracy}

The recovery of amoxapine in tablet formulation was ascertained by standard addition method. The preanalyzed tablet powder was spiked with pure drug at three different levels, $80 \%, 100 \%$, and $120 \%$ of the pre-analyzed tablet powder. The three replicates of each concentration were studied, and percentage of recovery was calculated. The results of accuracy are shown in Table 3.

\section{Precision}

The repeatability and intermediate precision of proposed method was analyzed on same day, different day and by different analyst. The results of precision studies are depicted in Table 4.

\section{Specificity}

The deliberated degradation of tablet sample was carried out in different condition such as acidic, basic, oxidative, thermal, and UV. The results are shown in Table 5.

Limit of detection (LOD) and limit of quantitation (LOQ)

The LOD and LOQ were calculated using formulae for LOD $(\mathrm{LOD}=3.3 \times \sigma / \mathrm{S})$ and $\mathrm{LOQ}(\mathrm{LOQ}=10 \times \sigma / \mathrm{S})$. Where $\sigma$ stands for standard deviation (SD) of the response and $\mathrm{S}$ stands for slope of calibration curve of the analyte. The results of LOD and LOQ are shown in Table 6.

\section{Robustness}

The robustness of proposed method was examined by doing small deliberate change in method parameters for instance, change in wavelength. The results are depicted in Table 7.

Table 1: Absorptivity value of amoxapine

\begin{tabular}{llll}
\hline Weights (mg) & Absorptivity value* & Mean \pm SD & \% RSD \\
\hline 10.1 & 206.46 & 206.80 & 0.606 \\
9.9 & 205.06 & \pm 1.253 & \\
10.1 & 206.46 & & \\
10.3 & 208.02 & & \\
10.2 & 208.04 & & \\
\hline
\end{tabular}

*Each value is mean of five observations. RSD: Relative standard deviation

Table 2: Application of proposed method for the analysis of amoxapine in tablet dosage form

\begin{tabular}{llll}
\hline $\begin{array}{l}\text { Weight of tablet } \\
\text { powder }(\mathrm{mg})\end{array}$ & Absorbance* & $\begin{array}{l}\text { \% Estimation* } \\
\text { mean } \pm \text { SD }\end{array}$ & \% RSD \\
\hline 28.84 & 0.209 & $100.32 \pm 0.931$ & 0.928 \\
\hline
\end{tabular}

*Value is a mean of six observations. SD: Standard deviation, RSD: Relative standard deviation 
Table 3: Results of recovery study

\begin{tabular}{lllll}
\hline Weight of tablet powder $(\mathbf{m g})$ & Absorbance & Amount recovered $(\boldsymbol{\mu g} / \mathbf{m L})$ & \% Recovery* mean \pm SD & \% RSD \\
\hline 28.47 & 0.354 & 18.37 & $102.09 \pm 0.724$ & 0.709 \\
27.74 & 0.380 & 19.68 & $98.44 \pm 0.897$ & 0.911 \\
26.05 & 0.425 & 22.02 & $100.09 \pm 0.942$ & 0.941 \\
\hline
\end{tabular}

*Value is mean of three determinations. RSD: Relative standard deviation, SD: Standard deviation

Table 4: Results of analysis of amoxapine on intraday, interday, and by different analyst

\begin{tabular}{llll}
\hline Amolife (Avg. wt. 137.71 $\mathbf{~ m g}$ for $\mathbf{5 0}$ mg of amoxapine) & Intraday & Interday & Different analyst \\
\hline Mean* \pm SD & $99.63 \pm 0.751$ & $99.80 \pm 0.510$ & $100.52 \pm 0.689$ \\
\% RSD & 0.753 & 0.511 & 0.686 \\
\hline
\end{tabular}

*Value is mean of six observations. RSD: Relative standard deviation, SD: Standard deviation

Table 5: Results of specificity studies

\begin{tabular}{llll}
\hline Conditions & $\begin{array}{l}\text { Weight of tablet } \\
\text { powder }(\mathbf{m g})\end{array}$ & $\begin{array}{l}\text { Percentage of } \\
\text { amoxapine* } \\
\text { mean } \pm \text { SD }\end{array}$ & \% RSD \\
\hline $0.1 \mathrm{~N} \mathrm{HCl}$ & 29.22 & $99.95 \pm 0.746$ & 0.746 \\
$0.1 \mathrm{~N} \mathrm{NaOH}$ & 30.14 & $99.27 \pm 0.985$ & 0.992 \\
$3 \% \mathrm{H} 202$ & 29.60 & $99.31 \pm 0.482$ & 0.485 \\
Thermal $\left(60^{\circ} \mathrm{C}\right)$ & 28.19 & $100.90 \pm 0.773$ & 0.766 \\
UV & 28.97 & $99.33 \pm 0.752$ & 0.757 \\
\hline
\end{tabular}

*Each value is mean of three observations. RSD: Relative standard deviation, UV: Ultraviolet, SD: Standard deviation

Table 6: Regression analysis

\begin{tabular}{ll}
\hline Parameters & Values \\
\hline Linearity range & $2-20 \mu \mathrm{g} / \mathrm{mL}$ \\
Correlation coefficient $(\mathrm{r})$ & 0.995 \\
Slope & 0.019 \\
LOD & 19.8 \\
LOQ & 60.50 \\
\hline
\end{tabular}

LOD: Limit of detection, LOQ: Limit of quantitation

Table 7: Results of robustness study

\begin{tabular}{lllll}
\hline Parameter & Amolife & Mean* & SD & \% RSD \\
\hline \multirow{2}{*}{ Wavelength } & $295 \mathrm{~nm}$ & 100.75 & 0.927 & 0.920 \\
& $299 \mathrm{~nm}$ & 99.51 & 0.759 & 0.763 \\
\hline
\end{tabular}

*Value is mean of three determinations. RSD: Relative standard deviation,

SD: Standard deviation

\section{DISCUSSION}

The proposed UV spectrophotometric method was successfully developed for estimation amoxapine in pharmaceutical formulation. As compared to earlier reported methods for the estimation of amoxapine, the proposed method is rapid, simple, and highly economic and therefore, useful for routine quantitative analysis of amoxapine. This method will reduce the tedious procedures involved in the preparation of sample and solvent system. The spectral analysis of amoxapine shows the maximum absorbance at wavelength $297 \mathrm{~nm}$ with linearity over the range of 2-20 $\mu \mathrm{g} / \mathrm{mL}$. The data of regression analysis are depicted in Table 6 . The results of the analysis and investigations of tablet formulation revealed that excipients of tablet formulation did not interfere with the analysis of amoxapine. The method was validated in terms of accuracy, precision, and robustness as per ICH guidelines. Almost 100\% recovery of drug confirmed that the proposed method is accurate whereas the low \% relative $S D$ value indicated high precision of the method with sufficient robustness.

\section{CONCLUSION}

From the results, it can be concluded that the developed UV spectrophotometric method is simple, precise, accurate, and costeffective and can be used for routine analysis of amoxapine.

\section{ACKNOWLEDGMENT}

First author would like to thank University Grants Commission, Government of India for Rajeev Gandhi National Research Fellowship and all authors thank Director, Mehta Pharmaceutical, India for providing gift sample of amoxapine.

\section{AUTHORS CONTRIBUTION}

First author SR conceptualized and designed the study, SP, RM and AH have assisted SR in the experimentation. SRwrote the manuscript and NAR optimized study design, supervised complete experimental work and completed finaldrafting of the manuscript. All correspondence of the manuscript were managed by NAR.

\section{CONFLICTS OF INTERESTS}

Authors declare no conflicts of interest.

\section{REFERENCES}

1. Lotfy HM, Saleh SS. Recent development in ultraviolet spectrophotometry through the last decade (2006-2016): A review. Int J Pharm Pharm Sci 2016;8:40-56.

2. Zadbuke N, Shahi S, Jadhav A, Borde S. Development and validation UV-visible spectrophotoscopic method for estimation of carbazepine in bulk and tablet dosage form. Int J Pharm Pharm Sci 2016;8:234-8

3. Jue S, Dawson G, Brogden, R. Amoxapine: A review of its pharmacology and efficacy in depressant state. Drug Eval 1982;24:1-23.

4. Apiquian R, Ulloa R, Fresan A, Loyzaga C, Nicolini H, Kapur S. Amoxapine shows atypical antipsychotic effect in patients with schizophrenia: Results from a prospective open-label study. Schizophr Res 2002;59:35-9.

5. Tassel J, Hassan F. Liquid chromatographic determination of amoxapine and 8-hydroamoxapine in human serum. Clin Chem 1982;28:2154-62.

6. Selinger K, Lebel G, Hill H, Anslow J. A high performance liquid chromatographic method for the analysis of amoxapine in human plasma. J Pharm Biomed Anal 1989;8:1001-7.

7. Vijaykrishna AC, Samir SP, Ahmed M, Shetty AS, Kuppast IJ, Anilkumar $\mathrm{SM}$, et al. RP-HPLC method development and validation for estimation of amoxapine in tablet dosage form. World J Pharm Pharm Sci 2015;4:1113-9.

8. Gupta M, Jain A, Verna K. Determination of Amoxapine and nortriptylline liquid-liquid micro extraction and high performance liquid chromatography. J Sep Sci 2010;33:3774-80.

9. Steven M, Jain A, Verna K. Determination of antidepressant, maprotiline and amoxapine and their metabolite in plasma by liquid chromatography. Clin Chem 1983;29:314-8.

10. Zimmer JS, Needham SR, Christianson CD, Piekarski CM, Sheaff CN, Huie $\mathrm{K}$, et al. Validation of HPLC-MS/MS methods for analysis of loxapine, amoxapine,7-OH-loxapine, 8-OH-loxapine and $\mathrm{N}$-oxide in human plasma. Bioanalysis 2010;2:1989-2000.

11. Karasakal A, Ulu S. Development and validation of a sensitive spectrfluoririmetric method for the determination of amoxapine in human plasma and urine. J Biol Chem Lumin 2013;29:284-7.

12. Korrapati U, Chintala R. New stability indicating RP-HPLC and spectrophotometric methods for the determination of amoxapine in tablet dosage form. Anal Chem 2016;16:147-56.

13. Patel S, Vijaykrishna C, Shetty S, Ahmad M. Development and validation of first order derivative spectrophotometric method for estimation of amoxapine in bulk and tablet dosage form. Int J Univ Pharm Biol Sci 2015;4:29-35.

14. International Conference of Harmonization: Q2 (R1) Validation of Analytical Procedure: Methodology: Geneva; 1996. 